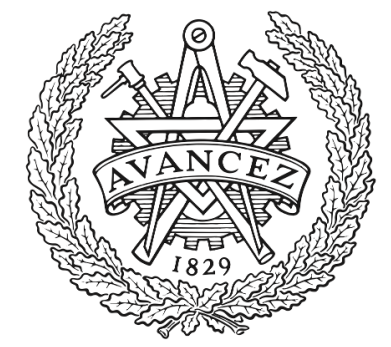

CHALMERS

UNIVERSITY OF TECHNOLOGY

\title{
Assessing the potential of wild yeasts for bioethanol production
}

Downloaded from: https://research.chalmers.se, 2023-04-26 06:20 UTC

Citation for the original published paper (version of record):

Ruyters, S., Mukherjee, V., J. Verstrepen, K. et al (2015). Assessing the potential of wild yeasts for bioethanol production. Journal of Industrial Microbiology and Biotechnology, 42(1): 39-48. http://dx.doi.org/10.1007/s10295-014-1544-y

N.B. When citing this work, cite the original published paper. 
See discussions, stats, and author profiles for this publication at: https://www.researchgate.net/publication/268790965

\section{Assessing the potential of wild yeasts for bioethanol production}

Article in Journal of Industrial Microbiology and Biotechnology · November 2014

DOI: 10.1007/s10295-014-1544-y · Source: PubMed

CITATIONS

31

6 authors, including:

Stefan Ruyters

KU Leuven, Campus De Nayer

69 PUBLICATIONS 511 CITATIONS

SEE PROFILE

Kevin J Verstrepen

KU Leuven

405 PUBLICATIONS 7,678 CITATIONS

SEE PROFILE

Some of the authors of this publication are also working on these related projects:

Project The potential of microbial volatiles mVOCs in parasitoids attraction View project

Project Sugar preferences \& longevitiy of hymenopteran parasitoids and their hyperparasitoid View project
READS

458

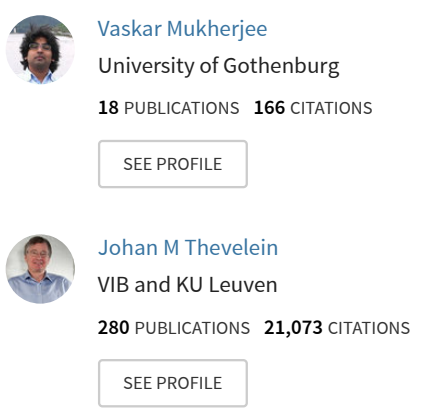


Springer Journal of Industrial Microbiology and Biotechnology 2014

Doi 10.1007/s10295-014-1544-y

http://link.springer.com/article/10.1007/s10295-014-1544-y

\section{Assessing the potential of wild yeasts for bioethanol production}

Stefan Ruyters $^{1 *}$, Vaskar Mukherjee ${ }^{1}$, Kevin J. Verstrepen ${ }^{2}$, Johan M. Thevelein ${ }^{3}$, Kris A. Willems ${ }^{1}$ and Bart Lievens ${ }^{1}$

${ }^{1} \mathrm{KU}$ Leuven, Laboratory for Process Microbial Ecology and Bioinspirational Management, Cluster for Bioengineering Technology (CBeT), Department of Microbial and Molecular Systems (M2S), Campus De Nayer, Fortsesteenweg 30A, B-2860 Sint-Katelijne-Waver, Belgium

${ }^{2}$ KU Leuven, Laboratory for Genetics and Genomics \& VIB Laboratory for Systems Biology, Centre of Microbial and Plant Genetics (CMPG), M2S, Gaston Geenslaan 1, B-3001 Leuven, Belgium

${ }^{3}$ KU Leuven, Laboratory of Molecular Cell Biology, Institute of Botany and Microbiology, and VIB Department of Molecular Microbiology, Kasteelpark Arenberg 31, B-3001 Leuven, Belgium

*corresponding author:

stefan.ruyters@kuleuven.be

Fortsesteenweg 30A, B-2860 Sint-Katelijne-Waver, Belgium

Tel +32 15305597

Fax +32 15305599

Key words: bioethanol, lignocellulose, nectar, Wickerhamomyces anomalus, thick juice 


\section{Abstract}

Bioethanol fermentations expose yeasts to a new, complex and challenging fermentation medium with specific inhibitors and sugar mixtures depending on the type of carbon source. It is therefore suggested that the natural diversity of yeasts should be further exploited in order to find yeasts with good ethanol yield in stressed fermentation media. In this study, we screened more than 50 yeast isolates of which we selected 5 isolates with promising features. The species Candida bombi, Wickerhamomyces anomalus and Torulaspora delbrueckii showed better osmo- and hydroxymethylfurfural tolerance than Saccharomyces cerevisiae. However, S. cerevisiae isolates had the highest ethanol yield in fermentation experiments mimicking high gravity fermentations (25\% glucose) and artificial lignocellulose hydrolysates (with a myriad of inhibitors). Interestingly, among two tested S. cerevisiae strains, a wild strain isolated from an oak tree performed better than Ethanol Red, a S. cerevisiae strain which is currently commonly used in industrial bioethanol fermentations. Additionally, a $W$. anomalus strain isolated from sugar beet thick juice was found to have a comparable ethanol yield, but needed longer fermentation time. Other non-Saccharomyces yeasts yielded lower ethanol amounts.

\section{Introduction}

In order to shift away from a petroleum-based energy source the European Union wants to establish the use of waste organic biomass as a renewable energy source. Currently used (so-called "first generation”) organic biomass sources are regular feedstocks with high sugar content (such as wheat, maize, sugar cane or beet) [34]. Whereas these sources might be suitable for high-end, but low quantity products, their role in bulk production of chemicals such as bioethanol is debated as they are competitive with food production. Indeed, it can cause an increase of the food price due to direct competition with the foodstock or through competition with agricultural land [7, 15]. Lignocellulosic biomass has therefore received increasing attention as an alternative for food energy crops. It is a renewable source originating from plant material, widely available and relatively inexpensive and can be non-competitive with food production [14]. 
The improved use of these types of biomass for bioethanol production yields some hurdles to be tackled. Very high gravity fermentations using first generation biomass [3] imply a high osmotic stress due to high sugar concentrations and high ethanol stress due to ethanol production during fermentation. Main added-value characteristics for bioethanol production strains are therefore high osmo- and ethanol tolerance. Lignocellulosic biomass is a more diverse and complex biomass compared to first generation biomass. It mainly consists of the sugar polymers cellulose and hemicellulose and the phenolic polymer lignin [18, 27, 29]. The cellulose fraction contains glucose monomers, while hemicellulose consists of a variety of C6 (mainly glucose) and C5 sugars (mainly xylose). These sugars are bound into the plant matrix and therefore need to be made available for fermentation by, for example, hydrolysis using acid or base at high temperature [22, 29, 37]. The liberated sugar concentration depends on the treatment type and intensity with high intensity treatments yielding higher sugar concentrations [37]. Typical total sugar concentrations vary between 100 to $200 \mathrm{~g} \mathrm{l}^{-1}$ with glucose concentrations about double of xylose concentrations [37]. While C6 sugars are readily fermented to ethanol by conventional yeasts such as Saccharomyces cerevisiae, $S$. cerevisiae is unable to utilize xylose [4]. The fermentation of xylose, however, contributes to an economically viable second generation bioethanol. Xylose can be fermented by some other yeasts, bacteria or fungi although by-product formation or slow xylose conversion may limit their economic application for ethanol production [32,34]. Recent research showed the potential of genetically engineering S. cerevisiae for the fermentation of xylose [10].

However, these intense treatments to release sugars also result in the formation of several undesired compounds in concentrations which may reduce the fermentation efficiency $[9,14,18,20,37]$. Most common inhibitors are weak acids such as levulinic acid, formic acid, acetic acid, furans such as 5hydroxymethylfurfural (HMF) and furfural and phenolic compounds resulting from the lignin fraction such as vanillin [14, 21, 37]. Typical concentrations of these compounds in hydrolysates are very variable as these are dependent on the biomass source, as well as the treatment procedure and intensity [37]. 
Due to the experience using $S$. cerevisiae in other industrial fermentations and the large amount of knowledge that has been gathered this species is also the first choice for bioethanol production [5]. It is especially useful in first generation bioethanol production due to its high ethanol yield and ethanol tolerance [38]. However, as outlined above, the fermentation environment in second generation bioethanol production differs greatly from any previous fermentation. In addition, due to large diversity of biomass sources and hydrolysis techniques and the concomitant diversity of the resulting hydrolysate mixture composition, it is required to align the hydrolysate with a yeast with the ideal characteristics. Therefore the natural diversity of yeasts should be further exploited in order to find yeasts with good ethanol yield in a fermentation medium containing high concentrations of glucose, containing a mixture of sugars such as glucose and xylose and/or a myriad of inhibitors. Surprisingly, so far only little is known on the relative ethanol yield of especially non-Saccharomyces yeasts under these conditions compared to $S$. cerevisiae.

In this study we examined several yeast species belonging to Candida, Starmerella, Metchnikowia, Pichia, Hanseniaspora, Torulaspora, Wickerhamomyces and Citeromyces which have been isolated from soil or sugar-rich habitats (floral nectar or sugar beet thick juice) for tolerance to inhibitors. Floral nectar and sugar beet thick juice are known for their low water activity ( $a_{w}$ less than 0.9$)$ due to high sugar concentrations and typically contain a limited number of specialized, xerotolerant yeasts [26]. In addition, nectar is also known for its diverse sugar composition [31]. In contrast to these sugar-rich habitats, soil contains a wide variety of different microorganisms. First, a large culture collection was screened for tolerance to osmotic stress, ethanol and HMF. Subsequently, tolerance to weak acids and furfural was examined on a selection of tolerant strains. Finally, 1.11 fermentation experiments with $25 \%$ glucose and experiments mimicking lignocellulosic hydrolysates were performed using the most promising strains and ethanol yield was recorded. 


\section{Materials and Methods}

\section{Culture collection}

A culture collection was constructed consisting of 56 yeast strains previously isolated from soil, plant nectar and sugar beet thick juice, i.e. an intermediate product from beet sugar production (Table 1) $[17,19]$. Except for soil, these habitats are known to be low in microbial diversity due to high osmotic stress. In total, 39 nectar isolates were included in this study, representing isolates from Candida bombi (14 isolates), Hanseniaspora uvarum (5), Metchnikowia reukauffii (11) and Starmerella bombicola (9). C. bombi and M. reukauffii were isolated from nectar of the same flower [17]. Further, the collection consisted of 12 isolates from beet sugar thick juice, representing isolates of Citeromyces matritensis (5), Torulaspora delbrueckii (3) and Wickerhamomyces anomalus (4). From soil one Pichia kudriavzevii isolate, one T. delbrueckii isolate and three Metchnikowia pulcherrima were included. Identifications were based on sequence analysis of the D1/D2 region of the large ribosomal subunit after PCR on the DNA extract [25] using primers NL1 and NL4 [24]. PCR conditions were as follows: 2 min at $94{ }^{\circ} \mathrm{C}, 35$ cycli of $45 \mathrm{~s}$ at $94{ }^{\circ} \mathrm{C}, 45 \mathrm{~s}$ at $55^{\circ} \mathrm{C}$ and $45 \mathrm{~s}$ at $72{ }^{\circ} \mathrm{C}$, followed by $10 \mathrm{~min}$ at $72{ }^{\circ} \mathrm{C}$ using Titanium Taq ((Clontech Laboratories, USA). Identification was performed by BLAST analysis in GenBank. To evaluate the phenotypic profile of these isolates in bioethanol production, a commercial S. cerevisiae strain currently used in bioethanol fermentation (Ethanol Red) and a 'wild' strain from oak (SCOak50) were used as a reference. All strains were stored in Yeast extract Peptone Dextrose (YPD) broth containing $25 \%$ glycerol at $-80{ }^{\circ} \mathrm{C}$.

\section{Phenotypic profiling}

First, the whole culture collection was screened on solid agar plates for a number of desirable traits, including osmotolerance (glucose 40-70 \% w/v), ethanol tolerance (5-15\% v/v) and HMF tolerance (2-7 $\left.\mathrm{g} \mathrm{l}^{-1}\right)$ as described by Mukherjee et al. [28]. Briefly, a basic growth medium (control medium) was prepared using bacto peptone $2 \% \mathrm{w} / \mathrm{v}(\mathrm{BD})$, yeast extract $1 \% \mathrm{w} / \mathrm{v}(\mathrm{LabM})$, glucose $2 \% \mathrm{w} / \mathrm{v}$ and agar $1.5 \% \mathrm{w} / \mathrm{v}$ (Invitrogen) . Further, test media were prepared containing the same basic composition as the control medium, but supplemented with the test compounds. Agar plates were prepared using 
Singer PlusPlates designed for use with the Singer ROTOR HDA robot (Singer Instruments, UK). Next, the 96 -well plate containing the strains stored at $-80{ }^{\circ} \mathrm{C}$ was thawed, spotted using the HDA robot on control medium containing $2 \%$ glucose and incubated at $30{ }^{\circ} \mathrm{C}$ for 2 days. Next, a 96 -well plate containing $150 \mu \mathrm{l}$ of liquid control medium in each well was inoculated with the strains using the robot and incubated overnight at $30{ }^{\circ} \mathrm{C}$ at $900 \mathrm{rpm}$ for preculturing. In case of screening for ethanol tolerance, strains were precultured for $48 \mathrm{~h}$ in liquid control medium with $2 \% \mathrm{v} / \mathrm{v}$ ethanol for preconditioning. Then, optical density at $600 \mathrm{~nm}\left(\mathrm{OD}_{600}\right)$ was measured using a microplate reader (Molecular Devices, USA) and the cell density was manually adjusted to $\mathrm{OD}_{600} \approx 0.2$. This plate was used as the source plate for spotting the test plates with the HDA rotor. After 5 days of incubation at $30{ }^{\circ} \mathrm{C}$ all test plates were scanned using a high definition scanner (Seiko Epson, Japan) and processed using ImageJ [1], combined with the ScreenMill software [11] especially developed to quantify the colony size of each isolate on the plates. Relative growth was calculated as the growth at a certain test condition relative to the growth on the control medium. Growth under a test condition is only considered when the relative growth exceeds $5 \%$ of the growth on the control medium.

In a second phase, the most promising strains (i.e. strains with good ethanol and HMF tolerance) were further evaluated for their growth in $2 \% \mathrm{w} / \mathrm{v}$ xylose liquid yeast extract bactopeptone (YP) medium. Growth in $2 \%$ xylose medium was evaluated by measuring the OD after $24 \mathrm{~h}$ of incubation at $30{ }^{\circ} \mathrm{C}$ in comparison with their growth in liquid medium containing $2 \%$ glucose. Additionally, tolerance to weak acids and furfural, both important inhibitors related to lignocellulosic hydrolysates was assessed. The assay was conducted in liquid medium using the OmniLog incubator/reader (Biolog, USA) which records color development due to metabolic activity. The assay was adapted from the general protocol as supplied by the manufacturer (Biolog, USA). The assay was performed in a 96-well plate in a total volume of $120 \mu$ l growth medium, consisting of yeast extract $\left(10 \mathrm{~g}^{-1}\right)$, bacto peptone $\left(20 \mathrm{~g} \mathrm{l}^{-1}\right), 6 \%$ w/v glucose and Biolog dye $\mathrm{D}(0.5 \mathrm{x}$ tetrazolium redox dye $)[13,35]$. Inhibitors were added at a concentration ranging from 10 to $40 \mathrm{mM}$ for acetic acid $\left(0.625-2.5 \mathrm{~g} \mathrm{l}^{-1}\right)$ and from 5 to $20 \mathrm{mM}$ for furfural (0.48-1.92 $\left.\mathrm{g} \mathrm{l}^{-1}\right)$, vanillin (0.76-3.04), formic acid (0.13-0.5 $\left.\mathrm{g} \mathrm{l}^{-1}\right)$ and levulinic acid (0.58-2.3 $\mathrm{g}$ $\left.1^{-1}\right)$. Prior to inoculation isolates were overnight pregrown on solid YPD agar and suspended in sterile 
demineralized water to an $\mathrm{OD}_{600}$ of 0.2 . Next, $125 \mu \mathrm{l}$ was added to $3 \mathrm{ml}$ sterile water of which then 90 $\mu 1$ was used as inoculum. The plates were incubated in the OmniLog instrument at $30{ }^{\circ} \mathrm{C}$ and the color development (due to the production of formazan from tetrazolium) at $36 \mathrm{~h}$ was recorded. Tolerance values were expressed relative to the growth without any inhibitors.

\section{Fermentation potential of selected isolates in high gravity and lignocellulosic medium}

Finally, these most promising isolates (one isolate from M. pulcherrima, P. kudriavzevii, $T$. delbrueckii, W. anomalus) were subjected to small scale fermentations (1.1 1) to estimate their ability to produce ethanol under high gravity ( $25 \%$ glucose) and lignocellulosic hydrolysate stress. As a reference the S. cerevisiae strains Ethanol Red and SCoak50 were included. Both strains had previously been shown to have an excellent tolerance profile (Table 1) [28]. Isolates were precultured overnight in $5 \mathrm{ml}$ YP medium containing $2 \%$ glucose, followed by inoculation in $300 \mathrm{ml}$ YP medium containing $10 \%$ glucose and incubation at $30{ }^{\circ} \mathrm{C}, 150 \mathrm{rpm}$ for 2 days until stationary phase. Next, $\mathrm{OD}_{600}$ was measured and a volume of it was harvested by centrifugation ( 5 minutes at $\left.3000 \mathrm{rpm}\right)$ that represented $\mathrm{OD}_{600} \approx 2.1$ and $\mathrm{OD}_{600} \approx 1.5$ in 1.11 high gravity and lignocellulosic hydrolysate stress fermentation medium, respectively. The latter fermentation medium consisted of $4.8 \% \mathrm{w} / \mathrm{v}$ glucose, $6.2 \% \mathrm{w} / \mathrm{v}$ xylose, $0.5 \% \mathrm{w} / \mathrm{v}$ mannose, $0.5 \% \mathrm{w} / \mathrm{v}$ galactose and $0.5 \% \mathrm{w} / \mathrm{v}$ arabinose and an inhibitor

concentration of $1.24 \mathrm{~g} \mathrm{l}^{-1} \mathrm{HMF}, 0.4 \mathrm{~g} \mathrm{l}^{-1}$ furfural, $2.3 \mathrm{~g} \mathrm{l}^{-1}$ acetic acid, $0.44 \mathrm{~g} \mathrm{l}^{-1}$ formic acid, $0.87 \mathrm{~g} \mathrm{l}^{-1}$ levulinic acid and $0.04 \mathrm{~g}^{-1}$ vanillin as described by Koppram et al. [21]. Concentrations are within the range tested in the liquid assay test. Batch fermentations were carried out using Eppendorf BioFlo reactors at a $\mathrm{pH}$ of $4.5,30{ }^{\circ} \mathrm{C}, 300 \mathrm{rpm}$ and saturated with air at the start of the fermentation. After the start of the fermentation dissolved oxygen was not further controlled and dropped quickly due to fermentation activity. During the fermentation $\mathrm{OD}_{600}$ was measured frequently and $1 \mathrm{ml}$ samples of the fermentation medium were taken, centrifuged and concentrations of ethanol, glucose and xylose in the supernatant were quantified using high performance liquid chromatography (HPLC) (Waters® isocratic Breeze $^{\mathrm{TM}}$ HPLC, ion exchange column WAT010290). Column temperature was maintained at $75{ }^{\circ} \mathrm{C}$, and $5 \mathrm{mM} \mathrm{H}_{2} \mathrm{SO}_{4}$ was used as eluent with a flow rate of $1 \mathrm{ml} \mathrm{min}{ }^{-1}$. A refractive index detector (Waters 2410, Waters, Milford, MA, USA) was used to detect the compounds of interest. 


\section{Results}

\section{Tolerance differences between yeast species of different genera}

In general, the non-Saccharomyces cerevisiae isolates were more tolerant to high glucose concentrations ( $>55 \%)$ than the two selected S. cerevisiae reference isolates (Table 1). These were previously shown to be among the top 20 most osmotolerant isolates from a collection of $280 \mathrm{~S}$. cerevisiae isolates [28]. Among the isolates from nectar, Candida bombi isolates showed the highest tolerance to glucose with an average relative growth (relative to the growth on $2 \%$ glucose) of $23 \%$ at a concentration of $55 \%$ glucose, and $24 \%$ at both 60 and $70 \%$ glucose. None of the nectar isolates from other genera, even when isolated from the same type of plant nectar, managed to grow at this concentration. Second best among the nectar yeasts was Starmerella bombicola with $24 \%$ relative growth at $55 \%$ glucose, $18 \%$ at $60 \%$ glucose, but none of the isolates did grow at $70 \%$ glucose (Table 1). Among the isolates from sugar beet thick juice, all isolates of Citeromyces matritensis managed to grow up to $60 \%$ glucose ( $25 \%$ relative growth), and three out of five isolates showed minor growth at $70 \%$ glucose. In contrast, the maximal glucose concentration at which isolates of Wickerhamomyces anomalus and Torulaspora delbrueckii isolates could grow was 55\% (28\% and 29\% relative growth, respectively, Table 1). Pichia kudriavzevii (soil) and Hanseniaspora uvarum (nectar), represented the least glucose-tolerant non-Saccharomyces species, and were able to grow up to $48 \%$ and $50 \%$ glucose, respectively (Table 1). As expected, S. cerevisiae strains were most tolerant to ethanol, tolerating $13 \%$ (SCOak50) and 14\% (Ethanol Red) ethanol. P. kudriavzevii isolated from soil was tolerant to $13 \%$ ethanol (Table 1). Non-Saccharomyces cerevisiae isolates showed considerable lower ethanol tolerance up to only $11 \% \mathrm{v} / \mathrm{v}$, with $M$. reukauffi, M. pulcherrima and H. uvarum showing no growth from $7 \% \mathrm{v} / \mathrm{v}$ ethanol onwards. At $10 \%$ and $11 \%$ ethanol only $W$. anomalus (18\% relative growth) and 1 T. delbrueckii isolate (5\%), all isolated from thick juice, were able to grow (Table 1). C. bombi and P. kudriavzevii isolates were the most tolerant to $\mathrm{HMF}$ as 42 and $39 \%$ relative growth was recorded at

$7 \mathrm{~g}^{-1} \mathrm{HMF}$, respectively. Other isolates did not manage to grow at this concentration, except for $S$. cerevisiae SCOak50 (Table 1). 


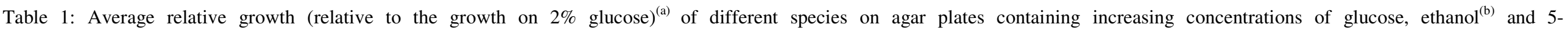
hydroxymethylfurfural with the standard error in brackets ${ }^{(c)}$. The number of isolates incorporated in the screening (\#) as well as the isolation source are given.

\begin{tabular}{|c|c|c|c|c|c|c|c|c|c|c|c|c|c|c|c|c|c|c|c|c|}
\hline \multirow[b]{2}{*}{ Species } & \multirow[b]{2}{*}{$\#$} & \multirow[b]{2}{*}{ Source } & \multicolumn{7}{|c|}{ Glucose $(\% \mathrm{w} / \mathrm{v})$} & \multicolumn{5}{|c|}{ Ethanol (\% v/v) } & \multicolumn{6}{|c|}{ 5-hydroxymethylfurfural $\left(\mathrm{g} \mathrm{l}^{-1}\right)$} \\
\hline & & & 40 & 46 & 48 & 50 & 55 & 60 & 70 & 5 & 7 & 10 & 11 & 12 & 2 & 3 & 4 & 5 & 6 & 7 \\
\hline Candida bombi & 14 & Nectar & $62(3)$ & $47(2)$ & $41(2)$ & $35(2)$ & $23(1)$ & $24(1)$ & $\underline{24}(2)$ & $\underline{52}(3)$ & $\underline{27}(2)$ & 0 & 0 & 0 & $98(4)$ & $\underline{108}$ (3) & $\underline{108}$ (3) & $\underline{87}(4)$ & $\underline{68}(4)$ & $\frac{51}{(3)}$ \\
\hline $\begin{array}{c}\text { Hanseniaspora } \\
\text { uvarum }\end{array}$ & 5 & Nectar & $27(1)$ & $19(0.4)$ & $11(2)$ & $8(1)$ & 0 & 0 & 0 & $18(3)$ & 0 & 0 & 0 & 0 & 47 (1) & $\underline{13}(2)$ & $\underline{12}(2)$ & 0 & 0 & 0 \\
\hline $\begin{array}{c}\text { Metchnikowia } \\
\text { reukauffii }\end{array}$ & 11 & Nectar & $31(1)$ & $28(2)$ & $23(1)$ & $17(1)$ & $10(1)$ & $7(1)^{*}$ & 0 & 0 & 0 & 0 & 0 & 0 & $49(6)$ & $\underline{\mathbf{1 7}}(8)$ & $\underline{17}(6)$ & 0 & 0 & 0 \\
\hline $\begin{array}{c}\text { Starmerella } \\
\text { bombicola }\end{array}$ & 9 & Nectar & $58(1)$ & $50(2)$ & $43(1)$ & $35(1)$ & $24(1)$ & $18(1)$ & 0 & $18(2)$ & $\underline{11}(2)$ & 0 & 0 & 0 & $79(6)$ & $66(10)$ & $62(9)$ & $25(8) *$ & $\underline{\mathbf{3 9}}$ (2) & 0 \\
\hline $\begin{array}{c}\text { Metchnikowia } \\
\text { pulcherrima }\end{array}$ & 2 & Soil & $75(1)$ & $46(2)$ & $46(3)$ & $36(5)$ & $37(2)$ & $19(4)$ & $\underline{9}$ & $15(3)$ & 0 & 0 & 0 & 0 & $\begin{array}{l}125 \\
(13)\end{array}$ & $\begin{array}{l}125 \\
(23)\end{array}$ & $\begin{array}{l}132 \\
(31)\end{array}$ & $\underline{13}(0)$ & 0 & 0 \\
\hline Pichia kudriavzevii & 1 & Soil & 114 & 14 & 9 & 0 & 0 & 0 & 0 & 116 & 120 & 85 & 64 & 42 & 78 & 70 & 71 & 57 & 46 & 39 \\
\hline $\begin{array}{l}\text { Citeromyces } \\
\text { matritensis }\end{array}$ & 5 & $\begin{array}{l}\text { Thick } \\
\text { juice }\end{array}$ & $76(3)$ & $43(4)$ & $67(4)$ & $51(5)$ & $36(4)$ & $25(3)$ & $\begin{array}{c}12 \\
(2)^{*}\end{array}$ & $\begin{array}{c}26 \\
(3)^{*}\end{array}$ & $\underline{19}$ & 0 & 0 & 0 & $12(2)^{*}$ & 0 & 0 & 0 & 0 & 0 \\
\hline $\begin{array}{c}\text { Torulaspora } \\
\text { delbrueckii }\end{array}$ & 4 & $\begin{array}{c}\text { Thick } \\
\text { juice (3) }\end{array}$ & $87(31)$ & $39(2)$ & $45(2)$ & $22(7)$ & $29(3)$ & $6(1)^{*}$ & 0 & $57(5)$ & $36(4)$ & $\underline{19}$ & $\underline{5}$ & 0 & $\begin{array}{c}45 \\
(16)^{*}\end{array}$ & $\begin{array}{c}46 \\
(12)^{*}\end{array}$ & $\begin{array}{c}30 \\
(14)^{*}\end{array}$ & $\underline{22}$ & $\underline{8}$ & 0 \\
\hline $\begin{array}{c}\text { Wickerhamomyces } \\
\text { anomalus }\end{array}$ & 4 & $\begin{array}{l}\text { Thick } \\
\text { juice }\end{array}$ & $161(37)$ & $45(10)$ & $\begin{array}{c}45 \\
(10)\end{array}$ & $28(6)$ & $28(4)$ & 0 & 0 & $\begin{array}{c}80 \\
(10)\end{array}$ & $59(7)$ & $\begin{array}{l}32 \\
(4)\end{array}$ & $\begin{array}{l}18 \\
(4)\end{array}$ & 0 & $86(14)$ & $74(16)$ & $69(15)$ & $24(9)$ & $\begin{array}{c}11 \\
(4)^{*}\end{array}$ & 0 \\
\hline $\begin{array}{c}\text { S. cerevisiae (EtOH } \\
\text { Red })\end{array}$ & 1 & $\begin{array}{l}\text { Bio- } \\
\text { ethanol }\end{array}$ & 42 & 42 & 24 & 15 & 0 & 0 & 0 & 101 & 102 & 85 & 81 & 73 & 138 & 129 & 129 & 33 & 0 & 0 \\
\hline $\begin{array}{l}\text { S. cerevisiae } \\
(\text { SCOak50) }\end{array}$ & 1 & oak & 39 & 44 & 25 & 17 & 0 & 0 & 0 & 94 & 95 & 79 & 73 & 60 & 86 & 75 & 87 & 86 & 38 & 15 \\
\hline
\end{tabular}

(a) Underlined values: 1 isolate did not grow and was not taken into account; * two isolates did not grow; Bold and underlined values: more than 50\% of the isolates did not grow

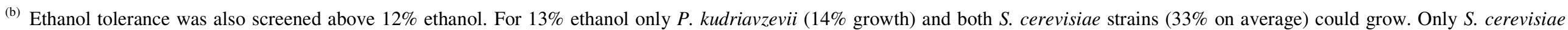
from bioethanol could grow on $14 \%$ ethanol $(22 \%)$

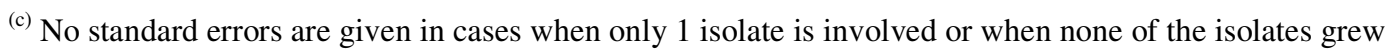




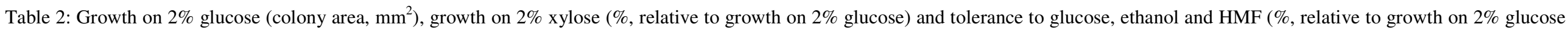
without inhibitors) and tolerance to weak acids, furfural and vanillin (\%, relative to metabolic activity in $6 \%$ glucose medium) of the best performing isolates of 5 genera.

\begin{tabular}{|c|c|c|c|c|c|c|c|c|c|c|c|c|c|c|c|c|c|c|c|}
\hline \multirow[t]{2}{*}{ Strain } & \multirow[t]{2}{*}{ Species } & \multirow[t]{2}{*}{$\begin{array}{l}\text { Isolation } \\
\text { source }\end{array}$} & \multicolumn{5}{|c|}{ Glucose $(\%$ w/v $)$} & \multirow{2}{*}{$\begin{array}{c}\text { Xylose } \\
(\% \text { w/v }) \\
2 \\
\end{array}$} & \multicolumn{3}{|c|}{ Ethanol $(\% \mathrm{v} / \mathrm{v})$} & \multicolumn{3}{|c|}{ HMF $\left(\mathrm{g} \mathrm{l}^{-1}\right)$} & \multirow{2}{*}{$\begin{array}{c}\text { Acetic } \\
\operatorname{acid}\left(\mathrm{g} \mathrm{l}^{-1}\right) \\
2.5\end{array}$} & \multirow{2}{*}{$\begin{array}{c}\text { Formic } \\
\text { acid }\left(\mathrm{g} \mathrm{I}^{-1}\right) \\
0.5\end{array}$} & \multirow{2}{*}{$\begin{array}{c}\text { Levulinic } \\
\text { acid }\left(\mathrm{g} \mathrm{l}^{-1}\right) \\
2.3\end{array}$} & \multirow{2}{*}{$\begin{array}{c}\text { Furfural } \\
\left(\mathrm{g} \mathrm{l}^{-1}\right) \\
1.44\end{array}$} & \multirow{2}{*}{$\begin{array}{c}\text { Vanillin } \\
\left(\mathrm{g} \mathrm{l}^{-1}\right) \\
0.76\end{array}$} \\
\hline & & & 2 & 46 & 55 & 60 & 70 & & 5 & 11 & 12 & 4 & 5 & 7 & & & & & \\
\hline Ethanol Red & $\begin{array}{l}\text { Saccharomyces } \\
\text { cerevisiae }\end{array}$ & Bioethanol & 742 & 42 & 0 & 0 & 0 & 3.5 & 101 & 81 & 73 & 129 & 33 & 0 & 94 & 89 & 94 & 6 & 86 \\
\hline SCOak50 & $\begin{array}{l}\text { Saccharomyces } \\
\text { cerevisiae }\end{array}$ & Oak & 707 & 44 & 0 & 0 & 0 & 9 & 94 & 73 & 60 & 87 & 86 & 15 & 106 & 105 & 125 & 9 & 88 \\
\hline ST1312/239 MP & $\begin{array}{l}\text { Metchnikowia } \\
\text { pulcherrima }\end{array}$ & Soil & 654 & 43 & 34 & 21 & 9 & 25 & 10 & 0 & 0 & 170 & 0 & 0 & 110 & 83 & 90 & 0 & 30 \\
\hline ST1312/061 PA G2 & $\begin{array}{l}\text { Wickerhamomyces } \\
\text { anomalus }\end{array}$ & Thick juice & 1127 & 25 & 19 & 0 & 0 & 24 & 73 & 22 & 0 & 61 & 30 & 0 & 89 & 94 & 89 & 0 & 99 \\
\hline ST1312/167 TD & $\begin{array}{l}\text { Torulaspora } \\
\text { delbrueckii }\end{array}$ & Thick juice & 1465 & 39 & 24 & 0 & 0 & 35 & 70 & 5 & 0 & 56 & 22 & 1 & 89 & 94 & 83 & 43 & 53 \\
\hline ST1312/230 PK & $\begin{array}{l}\text { Pichia } \\
\text { kudriavzevii }\end{array}$ & Soil & 1615 & 14 & 0 & 0 & 0 & 43 & 116 & 64 & 42 & 71 & 57 & 39 & 130 & 114 & 121 & 36 & 55 \\
\hline
\end{tabular}


However, at a more relevant HMF concentration of $4 \mathrm{~g} \mathrm{l}^{-1} 15$ isolates did not manage to grow, i.e. all C. matritensis isolates, 7 M. reukauffii isolates and 1 C. bombi, H. uvarum and T. delbrueckii. All W. anomalus (69\%), M. pulcherrima and S. bombicola strains (62\% growth) were able to grow (Table 1). M. reukauffii isolates showed variable tolerance, with four out of 11 isolates growing at $4 \mathrm{~g} \mathrm{l}^{-1} \mathrm{HMF}$ (17\% growth), while the others did only grow up to $2 \mathrm{~g} \mathrm{l}^{-1}$. Surprisingly, while the two M. pulcherrima isolates from soil showed $132 \%$ growth at $4 \mathrm{~g} \mathrm{l}^{-1}$, one did not grow at higher concentrations and the other one only $13 \%$ at $5 \mathrm{~g}^{-1}$ (Table1).

\section{Growth on xylose and tolerance to weak acids of selected yeast strains}

Due to their very low ethanol (less than 10\% v/v ethanol) and/or HMF tolerance isolates of C. bombi, H. uvarum, S. bombicola, C. matritensis and M. reukauffii were abandoned for further experiments as they have not the appropriate features for bioethanol production. From the species $W$. anomalus, $M$. pulcherrima, T. delbrueckii and P. kudriavzevii we selected 1 strain with the largest tolerance to glucose, ethanol and HMF (Table 2), and also both reference $S$. cerevisiae isolates were included. Growth in xylose medium was slower for all tested isolates compared to growth in glucose medium. Non $S$. cerevisae isolates grew generally better on xylose than $S$. cerevisiae strains $(<5 \%)$, especially W. anomalus PA G2, T. delbrueckii $167 \mathrm{TD}$ and P. kudriavzevii 230PK with growth $>20 \%$ compared to growth in $2 \%$ glucose medium (Table 2). Tolerance to weak acids was good for all strains as at least $80 \%$ relative metabolic activity was recorded at the highest tested concentrations for all tested weak acids (Table 2). T. delbrueckii 167TD and P. kudriavzevii 230PK showed highest tolerance to furfural, with recorded values of about $40 \%$ relative metabolic activity at $15 \mathrm{mM}$ furfural $\left(1.44 \mathrm{~g} \mathrm{l}^{-1}\right)$, while the other strains showed less than $10 \%$ activity. Nevertheless, at 5mM, only M.pulcherrima 230MP

and T. delbrueckii 167TD, showed considerable decrease in activity (30\% decrease). Both $S$. cerevisiae strains and W. anomalus 061P AG2 showed the best tolerance to vanillin with recorded values of $90-100 \%$ activity at $5 \mathrm{mM}(0.76 \mathrm{~g} / \mathrm{l})$, respectively, while the other strains showed at least $50 \%$ reduction (Table 2). No growth was recorded at $10 \mathrm{mM}$ vanillin for any of the strains. 


\section{Bioethanol production under high gravity and lignocellulosic hydrolysate stress}

Ethanol yield was recorded in $25 \%$ glucose fermentation medium. It was observed that S. cerevisiae and $W$. anomalus PA G2 yielded the highest ethanol concentrations (g ethanol/g glucose), up to the theoretical maximum of $50 \%$ (Table 3) which corresponds to $14 \% \mathrm{v} / \mathrm{v}$ ethanol. The other yeast isolates yielded $26-38 \%$ ethanol corresponding to $9-12 \% \mathrm{v} / \mathrm{v}$. Similar trends were observed for the lignocellulosic hydrolysate fermentations. There was no difference in ethanol yield in the presence and absence of inhibitors for all isolates, except for M. pulcherrima 230MP which did not yield any ethanol under inhibitor stress (Table 3). S. cerevisiae and W. anomalus PA G2 yielded the highest ethanol concentrations up to $61 \%$ of the total C6 sugars in the medium. Whereas both S. cerevisiae strains reached this value within $22 \mathrm{~h}$ (the first sampling point), W. anomalus PA G2 needed more time both in the absence (within 42h) and the presence (within $88 \mathrm{~h}$ ) of inhibitors (Table 3 and Fig. 1). At the time point with the maximal ethanol yield, about $10 \%$ of the xylose has been consumed by $S$. cerevisiae, probably because it was consumed for growth (Fig. 1, details not shown). W. anomalus PA G2 consumed $17 \%$ of the xylose in the absence of inhibitors and only $8 \%$ in the presence of inhibitors. The greatest decrease of xylose concentration was observed when glucose was still present and before the maximal ethanol yield was achieved (Fig. 1).

Table 3: Maximal ethanol yield (\%, g ethanol/g glucose) and the time (h) needed to reach this maximum for six selected yeast isolates in the presence of $25 \%$ glucose and the presence and absence of inhibitors ${ }^{(a)}$ (with a mixture of $5.8 \%$ C6 and $6.7 \%$ C5 sugars) related to lignocellulosic hydrolysates.

\begin{tabular}{|c|c|c|c|c|c|c|c|}
\hline \multirow[b]{3}{*}{ Isolate } & \multirow[b]{3}{*}{ Species } & \multirow{2}{*}{\multicolumn{2}{|c|}{$\begin{array}{l}\text { High gravity } \\
25 \% \text { glucose }\end{array}$}} & \multicolumn{4}{|c|}{ Lignocellulosic fermentation } \\
\hline & & & & \multicolumn{2}{|c|}{$\begin{array}{l}\text { Without } \\
\text { inhibitors }\end{array}$} & \multicolumn{2}{|c|}{ With inhibitors } \\
\hline & & $\begin{array}{c}\text { Max. } \\
\text { EtOH } \\
(\%)\end{array}$ & $\begin{array}{l}\text { Time } \\
\text { (h) }\end{array}$ & $\begin{array}{c}\text { Max. } \\
\text { EtOH } \\
(\%)\end{array}$ & $\begin{array}{l}\text { Time } \\
\text { (h) }\end{array}$ & $\begin{array}{c}\text { Max. } \\
\text { EtOH } \\
(\%)\end{array}$ & $\begin{array}{l}\text { Time } \\
\text { (h) }\end{array}$ \\
\hline EtOH Red & Saccharomyces cerevisiae & 49 & 114 & 54 & 19 & 56 & 19 \\
\hline SCOak50 & Saccharomyces cerevisiae & 50 & 52 & 62 & 22 & 61 & 22 \\
\hline $\begin{array}{c}\text { ST1312/239 } \\
\text { MP }\end{array}$ & Metchnikowia pulcherrima & 38 & 119 & 39 & 42 & 0 & 42 \\
\hline $\begin{array}{l}\text { ST1312/061 } \\
\text { PA G2 }\end{array}$ & Wickerhamomyces anomalus & 50 & 127 & 55 & 41 & 59 & 88 \\
\hline $\begin{array}{c}\text { ST1312/167 } \\
\text { TD }\end{array}$ & Torulaspora delbrueckii & 31 & 120 & 42 & 42 & 42 & 42 \\
\hline $\begin{array}{c}\text { ST1312/230 } \\
\text { PK }\end{array}$ & Pichia kudriavzevii & 26 & 138 & 43 & 22 & 45 & 22 \\
\hline
\end{tabular}



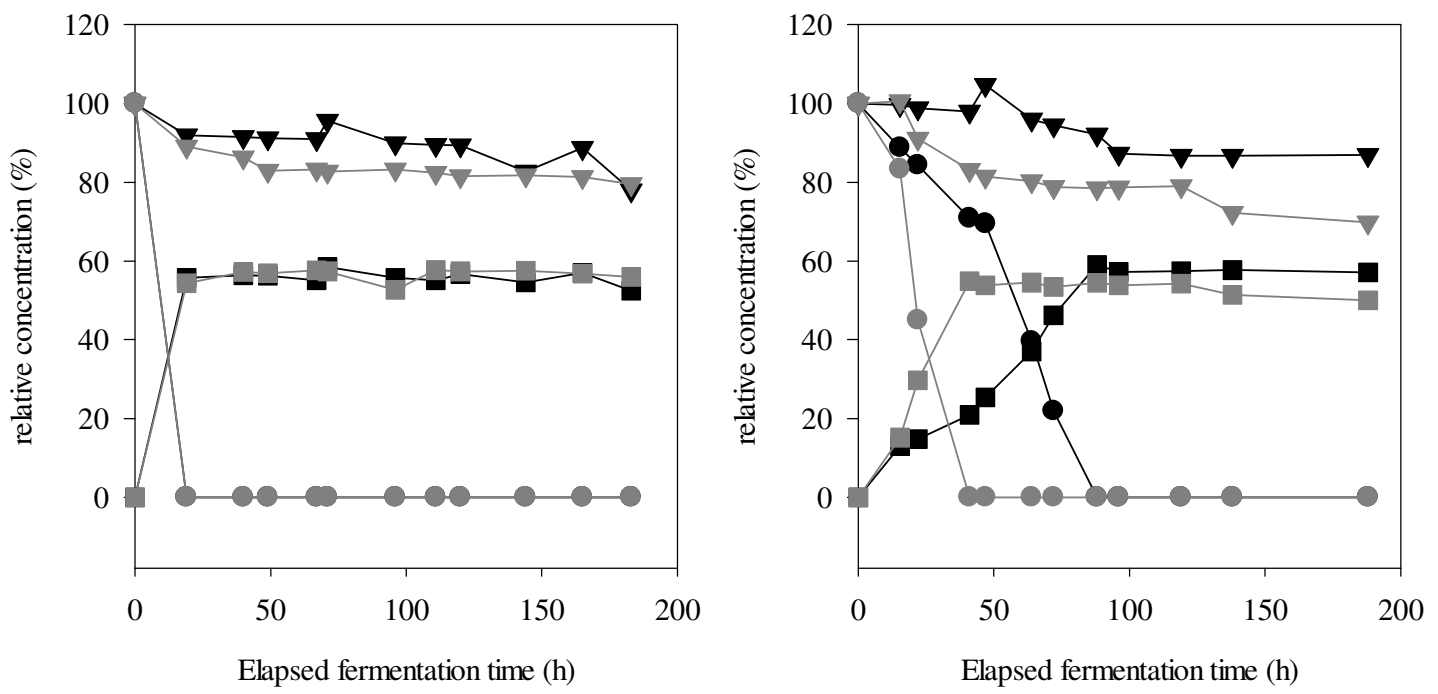

Fig. 1: Consumption of glucose (circles) and xylose (triangles) and production of ethanol (squares) in the presence (black) and absence (grey) of inhibitors for S. cerevisiae Ethanol Red (left) and W. anomalus PAG2 (right). Glucose and xylose values are relative to their respective values at the start of the fermentation, ethanol values are relative to the total C6 sugar content at the start. In case of Ethanol Red (left) the decrease of glucose is identical in the presence and absence of inhibitors and only the curve in the absence is visualized. Theoretically, 51g ethanol can be obtained from $100 \mathrm{~g}$ C6 sugars (51\%). The inhibitors concentrations are $1.24 \mathrm{~g}$ $\mathrm{l}^{-1} \mathrm{HMF}, 0.4 \mathrm{~g} \mathrm{l}^{-1}$ furfural, $2.3 \mathrm{~g} \mathrm{l}^{-1}$ acetic acid, $0.44 \mathrm{~g} \mathrm{l}^{-1}$ formic acid, $0.87 \mathrm{~g} \mathrm{l}^{-1}$ levulinic acid and $0.04 \mathrm{~g} \mathrm{l}^{-1}$ vanillin.

\section{Discussion}

Currently, S. cerevisiae is the organism of choice for fermentation processes producing ethanol [5].

However, bioethanol production from high sugar concentration feedstocks (such as maize, sugar beet) and lignocellulosic hydrolysates confronts the yeast with new challenges which were previously not encountered in any of the known fermentations [29, 38]. These include high ethanol tolerance and osmotolerance in case of high sugar feedstocks and tolerance to osmotic stress and a myriad of inhibitors in case of lignocellulosic hydrolysates. Also, the fermentation of xylose which cannot be performed by non-genetically engineered S. cerevisiae is important in the latter case. Exploiting the natural diversity of yeasts might expand the yeast strain repertoire with suitable characteristics for bioethanol fermentation. Some studies previously investigated the potential of non-S. cerevisiae yeasts. Huang et al. [16] and Cho et al. [8] showed that Scheffersomyces stipitis, a xylose fermenting yeast, had a poor growth rate when inhibitors were present. Blomqvist et al. [6] studied a Dekkera bruxellensis strain with better tolerance to inhibitors compared to a $S$. cerevisiae strain, and both strains had a comparable ethanol yield. Delgenes et al. [9] compared the effects of inhibitors on 
ethanol production by S. cerevisiae, Zymomonas mobilis, Pichia stipitis and Candida sheatae. Zha et al. [36] isolated Wickerhamomyces anomalus strains from grass silage that were tolerant to inhibitors. In this study we investigated yeasts isolated from a less commonly studied habitat, i.e. plant nectar and sugar beet thick juice (an intermediate product of sugar production stored in tanks) for their potential to tolerate osmostress, ethanol and HMF as lignocellulosic hydrolysate inhibitor and for their fermentation capacity. Nectar and sugar beet thick juice are known to house several yeast species which are less commonly isolated from typical habitats such as water or soil $[2,26]$. In addition, these environments are rather distinct from typical habitats as they contain high concentrations of sugars and/or a myriad of different sugars $[12,26]$ and are therefore microbially less diverse compared to other environmental habitats.

Our results, as summarized in Table 1, showed that Metchnikowia reukauffii, Hanseniaspora uvarum and Starmerella bombicola isolates, isolated from nectar, showed poor characteristics for bioethanol fermentation, even for low sugar feedstocks, due to a low ethanol tolerance with growth being severely impaired from 5\% v/v onwards. Also Citeromyces matritensis isolates isolated from sugar beet thick juice showed poor ethanol tolerance. Also, the low HMF tolerance of these four species would impede their use in the fermentation of lignocellulosic hydrolysates. Candida bombi isolates from nectar, however, showed a very good osmotolerance (up to 70\%) and HMF tolerance (up to $7 \mathrm{~g} \mathrm{l}^{-}$ $\left.{ }^{1}\right)$. However, its low ethanol tolerance might impede its use in bioethanol fermentation of first generation and even of lignocellulosic hydrolysates as ethanol concentrations of $5 \%$ are readily obtained during fermentation. Similar conclusions can be drawn for three out of four Torulaspora delbrueckii isolates, however, they have a lower tolerance to HMF than C. bombi. One T. delbrueckii showed better ethanol and HMF tolerance and was therefore selected for further experiment. The most promising species is Wickerhamomyces anomalus. Although its osmotolerance and HMF tolerance to high concentrations is generally lower than $C$. bombi isolates, it is still good at relevant concentrations for bioethanol production. In addition, ethanol tolerance is much better than C. bombi with growth still recorded up to $11 \%$ ethanol. W. anomalus isolate PA G2 also performed best on xylose (Table 2). This suggests that $W$. anomalus might be interesting for the fermentation of xylose in lignocellulosic hydrolysates. Zha et al. [36] previously identified W. anomalus isolates as good candidates for 
lignocellulosic hydrolysate fermentation as they showed good resistance to HMF and other inhibitors and growth on xylose as carbon source. In addition, $W$. anomalus might be an interesting species in unsterile fermentations due to its killer activity and biocontrol activity which outcompetes other microorganism during fermentation, such as lactic acid bacteria or other yeasts [30].

Next to tolerance to fermentation inhibitors ethanol yield is also an important parameter. Therefore, we conducted fermentation experiments under controlled conditions using Bioflo bioreactors and measured glucose, xylose and ethanol during the course of the experiment. A high sugar medium containing $25 \%$ glucose and an artificial lignocellulosic hydrolysate medium was used to test 4 strains selected based on their tolerance. Two $S$. cerevisiae strains were included as reference, since this species is known for its excellent ethanol yield [33]. One strain is used as industrial bioethanol strain, the other strain is a natural strain isolated from oak and not domesticated for use in fermentation processes. The concentrations of the individual inhibitors in the lignocellulosic hydrolysate medium were similar to the concentrations tested in the liquid assay that not impaired metabolic activity. Our results confirmed the excellent ethanol yield of S. cerevisiae compared to other species (Table 3). Both strains yielded an ethanol concentration close to the theoretically maximal yield based on C6 sugars (51\%), while the ethanol yield for the selected M. pulcherrima, T. delbrueckii and P. kudriavzevii strains ranged from 26-38\%. The selected $W$. anomalus strain also yielded 50\% ethanol per g glucose. This is in agreement with the study of Passoth et al. [30] that showed that W. anomalus has a good ethanol yield. Both S. cerevisiae and W. anomalus also showed good ethanol tolerance during these fermentation (up to $14 \% \mathrm{v} / \mathrm{v}$ ethanol), which is essential in high gravity fermentation. Similar trends were observed in the lignocellulosic hydrolysate medium without inhibitors containing about $20 \%$ total sugars. Except for M. pulcherrima which yielded no ethanol in the presence of inhibitors, no effect of the presence of inhibitors on the ethanol yield was observed for any of the strains. Both $S$. cerevisiae strains performed equally good with the oak derived strain even more tolerant to HMF, showing that good bioethanol production strains for both first and second generation biomass might be omnipresent in nature. In contrast to the $25 \%$ glucose fermentation, ethanol yield was above the theoretical value of $51 \%$. Conversion of inhibitors to ethanol is unlikely explaining this, because this is also observed in the absence of inhibitors. Conversion of C5 sugars to ethanol might explain this, 
however, this is not expected for S. cerevisiae that also showed increased ethanol yield. The ethanol yield of the W. anomalus strain was similar to that of both S. cerevisiae strains, however, the presence of inhibitors decreased the rate of ethanol production. This shows that W. anomalus might be interesting as bioethanol production strain for lignocellulosic hydrolysates if it is able to ferment xylose to ethanol. However, when pregrown on glucose it was shown that xylose was consumed along with glucose consumption, but once glucose was depleted xylose consumption decreased. This interrupted xylose consumption of W. anomalus was also observed by Zha et al. [36] and Kurtzman [23] and was contributed to the lack of oxygen present. This might suggest that xylose was not converted to ethanol during the first stage either, but rather used for aerobic growth. Indeed, the ethanol yield based on C6 sugars was similar to both S. cerevisiae strains which do not ferment xylose. Pregrowth of $W$. anomalus on $10 \%$ xylose did not make any difference in ethanol production and xylose or glucose consumption during fermentation compared to pregrowth on $10 \%$ glucose (data not shown). Similar ethanol yields were obtained and only $10 \%$ of xylose was consumed.

\section{Acknowledgement}

The authors would like to thank Marijke Lenaerts for help with sampling yeasts from nectar, Laetitia Six for help with sampling the bioreactors outside regular office hours, Ado Van Assche for assistance with Omnilog, Jan Steensels and Tim Snoeck for providing assistance with the Singer HDA robot and Françoise Dumortier for providing assistance with HPLC analysis. This work was funded by the IOFKP/10/002 granted by KU Leuven. 


\section{References}

1. Abramoff MD, Magalhaes PJ, Ram SJ (2004) Image processing with ImageJ. Biophotonics International $11(7): 36-42$

2. Álvarez-Pérez S, Herrera CM (2013) Composition, richness and nonrandom assembly of culturable bacterial-microfungal communities in floral nectar of Mediterranean plants. Fems Microbiol Ecol 83 (3):685-699. doi: 10.1111/1574-6941.12027

3. Bai FW, Anderson WA, Moo-Young M (2008) Ethanol fermentation technologies from sugar and starch feedstocks. Biotechnol Adv 26 (1):89-105. doi: 10.1016/j.biotechadv.2007.09.002

4. Barnett JA (1976) The utilization of sugars by yeasts. Adv Carbohydr Chem and Biochem (32):125234. doi: 10.1016/S0065-2318(08)60337-6

5. Basso LC, De Amorim HV, De Oliveira AJ, Lopes ML (2008) Yeast selection for fuel ethanol production in Brazil. FEMS Yeast Res 8 (7):1155-1163. doi:10.1111/j.1567-1364.2008.00428.x

6. Blomqvist J, South E, Tiukova L, Momeni MH, Hansson H, Ståhlberg J, Horn SJ, Schnürer J, Passoth V (2011) Fermentation of lignocellulosic hydrolysate by the alternative industrial ethanol yeast Dekkera bruxellensis. Lett Appl Microbiol 53 (1):73-78. doi: 10.1111/j.1472765X.2011.03067.x

7. Campbell JE, Block E (2010) Land-Use and Alternative Bioenergy Pathways for Waste Biomass. Environ Sci Technol 44 (22):8665-8669. doi: 10.1021/es100681g

8. Cho DH, Shin SJ, Bae Y, Park C, Kim YH (2011) Ethanol production from acid hydrolysates based on the construction and demolition wood waste using Pichia stipitis. Bioresour Technol 102 (6):44394443. doi:10.1016/j.biortech.2010.12.094

9. Delgenes JP, Moletta R, Navarro JM (1996) Effects of lignocellulose degradation products on ethanol fermentations of glucose and xylose by Saccharomyces cerevisiae, Zymomonas mobilis, Pichia stipitis, and Candida shehatae. Enzyme Microb Technol 19 (3):220-225. doi:http://dx.doi.org/10.1016/0141-0229(95)00237-5 
10. Demeke M, Dietz H, Li Y, Foulquié-Moreno M, Mutturi S, Deprez S, Den Abt T, Bonini B, Lidén G, Dumortier F, Verplaetse A, Boles E, Thevelein J (2013) Development of a D-xylose fermenting and inhibitor tolerant industrial Saccharomyces cerevisiae strain with high performance in lignocellulose hydrolysates using metabolic and evolutionary engineering. Biotechnol Biofuels 6 (1):89

11. Dittmar J, Reid R, Rothstein R (2010) ScreenMill: A freely available software suite for growth measurement, analysis and visualization of high-throughput screen data. BMC Bioinformatics 11 (1):353. doi: 10.1186/1471-2105-11-353

12. Gonzalez-Teuber M, Heil M (2009) Nectar chemistry is tailored for both attraction of mutualists and protection from exploiters. Plant Signal Behav 4 (9):809-813. doi:10.4161/psb.4.9.9393

13. Greetham D, Wimalasena T, Kerruish DWM, Brindley S, Ibbett RN, Linforth RL, Tucker G, Phister TG, Smart KA (2014) Development of a phenotypic assay for characterisation of ethanologenic yeast strain sensitivity to inhibitors released from lignocellulosic feedstocks. J Ind Microbiol Biotechnol 41 (6):931-945. doi:10.1007/s10295-014-1431-6

14. Hahn-Hägerdal B, Galbe M, Gorwa-Grauslund MF, Lidén G, Zacchi G (2006) Bio-ethanol - the fuel of tomorrow from the residues of today. Trends Biotechnol 24 (12):549-556. doi: 10.1016/j.tibtech.2006.10.004

15. Hamelinck CN, Faaij APC (2006) Outlook for advanced biofuels. Energy Policy 34 (17):32683283. doi: 10.1016/j.enpol.2005.06.012

16. Huang C-F, Lin T-H, Guo G-L, Hwang W-S (2009) Enhanced ethanol production by fermentation of rice straw hydrolysate without detoxification using a newly adapted strain of Pichia stipitis. Bioresour Technol 100 (17):3914-3920. doi: 10.1016/j.biortech.2009.02.064

17. Jacquemyn H, Lenaerts M, Brys R, Willems K, Honnay O, Lievens B (2013) Among-population variation in microbial community structure in the floral nectar of the bee-pollinated forest herb Pulmonaria officinalis L. Plos One 8 (3):e56917. doi: 10.1371/journal.pone.0056917 
18. Jonsson L, Alriksson B, Nilvebrant N-O (2013) Bioconversion of lignocellulose: inhibitors and detoxification. Biotechnol Biofuels 6 (1):16

19. Juste A, Lievens B, Frans I, Klingeberg M, Michiels CW, Willems KA (2008) Present knowledge of the bacterial microflora in the extreme environment of sugar thick juice. Food Microbiol 25 (6):831-836. doi: 10.1016/j.fm.2008.04.010

20. Klinke HB, Thomsen AB, Ahring BK (2004) Inhibition of ethanol-producing yeast and bacteria by degradation products produced during pre-treatment of biomass. Appl Microbiol Biotechnol 66 (1):1026. doi: $10.1007 / \mathrm{s} 00253-004-1642-2$

21. Koppram R, Albers E, Olsson L (2012) Evolutionary engineering strategies to enhance tolerance of xylose utilizing recombinant yeast to inhibitors derived from spruce biomass. Biotechnol Biofuels 5 (1):32

22. Kumar P, Barrett DM, Delwiche MJ, Stroeve P (2009) Methods for Pretreatment of Lignocellulosic Biomass for Efficient Hydrolysis and Biofuel Production. Ind Eng Chem Res 48 (8):3713-3729. doi: 10.1021/ie801542g

23. Kurtzman CP (1998) Pichia E. C. Hansen emend. Kurtzman. The yeasts, a taxonomic study, Fourth edition, 5th edn. Elsevier Science Publishers B.V., Amsterdam, The Netherlands. doi: $10.1016 / \mathrm{b} 978-044481312-1 / 50046-0$

24. Kurtzman CP, Robnett CJ (1997) Identification of clinically important ascomycetous yeasts based on nucleotide divergence in the $5^{\prime}$ end of the large-subunit (26S) ribosomal DNA gene. J Clin Microbiol 35 (5):1216-1223

25. Lievens B, Brouwer M, Vanachter ACRC, Lévesque CA, Cammue BPA, Thomma BPHJ (2003) Design and development of a DNA array for rapid detection and identification of multiple tomato vascular wilt pathogens. Fems Microbiol Lett 223 (1):113-122. doi: 10.1016/S0378-1097(03)00352-5 
26. Lievens B, Hallsworth JE, Pozo MI, Belgacem ZB, Stevenson A, Willems KA, Jacquemyn H (2014) Microbiology of sugar-rich environments: diversity, ecology, and system constraints. Env Microbiol: doi: 10.1111/1462-2920.12570

27. Limayem A, Ricke SC (2012) Lignocellulosic biomass for bioethanol production: Current perspectives, potential issues and future prospects. Prog Energ Combust Sci 38 (4):449-467. doi: 10.1016/j.pecs.2012.03.002

28. Mukherjee V, Steensels J, Lievens B, Van de Voorde I, Verplaetse A, Aerts G, Willems KA, Thevelein JM, Verstrepen KJ, Ruyters S (2014) Phenotypic evaluation of natural and industrial Saccharomyces yeasts for different traits desirable in industrial bioethanol production. Appl Microbiol Biotechnol (ahead of print). doi: 10.1007/s00253-014-6090-z

29. Palmqvist E, Hahn-Hagerdal B (2000) Fermentation of lignocellulosic hydrolysates. II: inhibitors and mechanisms of inhibition. Bioresour Technol 74 (1):25-33. doi: 10.1016/s0960-8524(99)00161-3

30. Passoth V, Fredlund E, Druvefors UA, Schnurer J (2006) Biotechnology, physiology and genetics of the yeast Pichia anomala. FEMS Yeast Res 6 (1):3-13. doi: 10.1111/j.1567-1364.2005.00004.x

31. Pozo MI, Lievens B, Jacquemyn H (2014) Impact of Microorganisms on Nectar Chemistry, Pollinator Attraction and Plant Fitness. In: Nectar: Production, Chemical Composition and Benefits to Animals and Plants. Nova Science Publishers, Inc., New York, USA,

32. Toivola A, Yarrow D, van den Bosch E, van Dijken JP, Scheffers WA (1984) Alcoholic Fermentation of d-Xylose by Yeasts. Appl Environ Microbiol 47 (6):1221-1223

33. van Maris AJA, Abbott DA, Bellissimi E, van den Brink J, Kuyper M, Luttik MAH, Wisselink HW, Scheffers WA, van Dijken JP, Pronk JT (2006) Alcoholic fermentation of carbon sources in biomass hydrolysates by Saccharomyces cerevisiae: current status. Antonie Van Leeuwenhoek 90 (4):391-418. doi: 10.1007/s10482-006-9085-7

34. Waites MJ, Morgan NL, Rockey JS, Higton G (2001) Industrial Microbiology: An introduction. first edition edn. Blackwell Science, Oxford 
35. Wimalasena T, Greetham D, Marvin M, Liti G, Chandelia Y, Hart A, Louis E, Phister T, Tucker G, Smart K (2014) Phenotypic characterisation of Saccharomyces spp. yeast for tolerance to stresses encountered during fermentation of lignocellulosic residues to produce bioethanol. Microb Cell Fact $13(1): 47$

36. Zha Y, Hossain AH, Tobola F, Sedee N, Havekes M, Punt PJ (2013) Pichia anomala 29X: a resistant strain for lignocellulosic biomass hydrolysate fermentation. FEMS Yeast Res 13 (7):609-617. doi: $10.1111 / 1567-1364.12062$

37. Zha Y, Muilwijk B, Coulier L, Punt P (2012) Inhibitory Compounds in Lignocellulosic Biomass Hydrolysates during Hydrolysate Fermentation Processes. J Bioprocess biotechniq 2 (112). doi: $10.4172 / 2155-9821.1000112$

38. Zhao XQ, Bai FW (2009) Mechanisms of yeast stress tolerance and its manipulation for efficient fuel ethanol production. J Biotechnol 144 (1):23-30. doi: 10.1016/j.jbiotec.2009.05.001

\section{Figure caption}

Fig. 1 Consumption of glucose (circles) and xylose (triangles) and production of ethanol (squares) in the presence (black) and absence (grey) of inhibitors for S. cerevisiae Ethanol Red (left) and $W$. anomalus PAG2 (right). Glucose and xylose values are relative to their respective values at the start of the fermentation, ethanol values are relative to the total C6 sugar content at the start. In case of Ethanol Red (left) the decrease of glucose is identical in the presence and absence of inhibitors and only the curve in the absence is visualized. Theoretically, 51g ethanol can be obtained from 100g C6 sugars (51\%). The inhibitors concentrations are $1.24 \mathrm{~g} \mathrm{l}^{-1} \mathrm{HMF}, 0.4 \mathrm{~g} \mathrm{l}^{-1}$ furfural, $2.3 \mathrm{~g} \mathrm{l}^{-1}$ acetic acid, $0.44 \mathrm{~g} \mathrm{l}^{-1}$ formic acid, $0.87 \mathrm{~g} \mathrm{l}^{-1}$ levulinic acid and $0.04 \mathrm{~g} \mathrm{l}^{-1}$ vanillin. 